\title{
O PAPEL DAS CONSULTAS PÚBLICAS NA GESTÃO DE RISCOS AMBIENTAIS: UM OLHAR AOS PROJECTOS DE PETRÓLEO E GÁS EM MOÇAMBIQUE
}

\author{
Manuel Pastor Francisco Conjo ${ }^{1}$ \\ Ajosia da Lídia Basílio Muipela António ${ }^{2}$ \\ Arlene Atija de Fátima Cebola Lucas Momade ${ }^{3}$ \\ Hortência Luísa Tole Tambo Foquiço ${ }^{4}$ \\ Neci da Conceição Nunes Gimo ${ }^{5}$
}

RESUMO: A indústria do petróleo e gás, desenvolve uma actividade bastante complexa, que para chegar ao seu produto final, diversos riscos são gerados, dentre eles, riscos ambientais. $\mathrm{O}$ presente trabalho traz uma reflexão acerca da comunicação de riscos por meio de consultas públicas para a gestão de riscos ambientais, com particular enfoque para os projectos de petróleo e gás em Moçambique. O presente estudo foi realizado por meio de revisão da literatura existente sobre esta temática, e os resultados revelaram que as consultas públicas jogam um papel fundamental na gestão de riscos, uma vez que a comunicação de riscos, por meio de consultas públicas, é reforçada a participação pública nos processos de tomada de decisão, contribuindo na transparência dos processos e na recepcção aberta de opiniões públicas, aspectos fundamentais para a gestão de riscos através do envolvimento de todos os intervenientes. Mas para que as consultas públicas sejam eficazes, devem ser estruturadas para determinados grupos alvos e temáticas específicas, segundo a complexidade do projecto, e por isso recomenda-se a elaboração de instrumentos legais que orientem os processos de consultas públicas específicos para projectos de petróleo e gás offshore (no mar) e onshore (na terra).

Palavras-chave: Gestão de Riscos. Petróleo e gás. Consultas Públicas.

ABSTRACT: The oil and gas industry develop a very complex activity, which in order to reach its final product, several risks are generated, among them, environmental risks. The present work presents a reflection on risk communication through public consultations for the management of environmental risks, with a particular focus on oil and gas projects in Mozambique. The present study was carried out through a review of the existing literature on this topic, and the results revealed that public consultations play a fundamental role in risk management, since risk communication, through public consultations, is reinforced public

\footnotetext{
I Doutorando em Ciência Florestal pela Universidade Federal de Viçosa Minas Gerais - Brasil. Mestrado em Gestão Ambiental pela Universidade Pedagógica de Maputo - Moçambique. Bacharel e Licenciado em Ensino de Geografia pela Universidade Pedagógica de Maputo - Moçambique. Técnico Superior em Higiene e Segurança no Trabalho e Meio Ambiente pela Ensine Moçambique. E-mail:m.conjo@hotmail.com.

${ }^{2}$ Mestranda em Gestão Ambiental na Faculdade de Ciências da Terra e Ambiente, Universidade Pedagógica de Maputo. Licenciada em Ciências Biológicas pela Universidade Lúrio.. Email: amuipela@gmail.com

${ }_{3}^{3}$ Mestranda em Gestão Ambiental na Faculdade de Ciências da Terra e Ambiente, Universidade Pedagógica de Maputo. Licenciada em Geografia pela Universidade Eduardo Mondlane. Email: arlenemomadeo8@gmail.com ${ }_{4}$ Mestranda em Gestão Ambiental na Faculdade de Ciências da Terra e Ambiente, Universidade Pedagógica de Maputo. Profissional de segurança no trabalho, ambiente e qualidade. Consultora e auditoria ambiental, certificação pelo Ministério da Terra e Ambiente. Bacharel e Licenciada em Gestão ambiental, Planificação e Desenvolvimento Comunitário pela Universidade Pedagógica Delegação da Beira, actual Universidade Licungo. Email: hortambo@gmail.com

5 Mestranda em Gestão Ambiental na Faculdade de Ciências da Terra e Ambiente, Universidade Pedagógica de Maputo. Bacharel e Licenciada em Ensino de Geografia pela Universidade Pedagógica de Maputo. Email: necicgimo@gmail.com.
} 
participation in decision-making processes, contributing to the transparency of processes and the open reception of public opinions, fundamental aspects for risk management through the involvement of all stakeholders. But in order for public consultations to be effective, they must be structured for specific target groups and specific themes, according to the complexity of the project, and for this reason it is recommended the elaboration of legal instruments that guide the processes of specific public consultations for oil and gas projects. offshore (at sea) and onshore (on land) gas.

Keywords: Risk Management. Oil and Gas. Public Consultations.

\section{INTRODUÇÃO}

A indústria do petróleo e gás, desenvolve uma actividade bastante complexa, que para chegar ao seu produto final, diversos riscos são gerados durante esse processo produtivo, que podem colocar em risco a saúde e a integridade física dos trabalhadores, assim como riscos ao ambiente e as comunidades circunvizinhas.

O progresso que a indústria de petróleo e gás vem registando em Moçambique, devido a descoberta de grandes quantidades de reserva de gás na bacia do Rovuma, tem despertado no público expectativas mas também interesse sobre os riscos e impactos sobre as actividades que serão desenvolvidas nestes projectos com maior destaque para os negativos, o que impõe ao regulador e as organizações a uma avaliação dos métodos de gestão de riscos a serem implementados, e desta forma, a percepção de risco é elemento fundamental não só para a sua gestão, mas está inclusa na sua actual definição. A sua análise tem sido parte dos estudos ambientais a serem elaborados no âmbito do processo de licenciamento ambiental, sendo que no caso das actividades de exploração e produção de petróleo e gás é requerido tendo em conta os prováveis impactos sobre os recursos ambientais e a vida das comunidades.

Os riscos ambientais remetem à possibilidade de ocorrência de eventos danosos ao ambiente, e estes quase sempre são vistos como um objecto social, podendo afectar uma comunidade ou indivíduos específicos, tornando-se o Homem a figura central nesta temática. Os riscos ambientais estão presentes em todas actividades, caracterizadas pelo seu efeito de incertezas nos objectivos, podendo estes terem diferentes aspectos tais como as metas ambientais, sendo também representados pela combinação das consequências de um evento e a probabilidade de ocorrência do mesmo. 
Este trabalho pretende trazer a compreensão do papel das consultas públicas na gestão de riscos ambientais, com particular enfoque para os projectos de petróleo e gás em Moçambique, buscando contribuir com as questões teóricas, na identificação de abordagens metodológicas da comunicação pública dos riscos para uma melhor gestão dos mesmos, como forma de melhor desenvolvimento social dos projectos de petróleo e gás em Moçambique, melhorando assim, o quotidiano das comunidades e garantir uma futura qualidade de vida das pessoas.

\section{A Indústria de Petróleo e Gás}

O petróleo e gás são recursos essenciais à sociedade, pois beneficiam vários aspectos do dia-a-dia, como os produtos utilizados nos diversos sectores industriais. Porém para que isso ocorra é necessário que este recurso passe por várias etapas de processos (SANTOS, 2012).

De acordo com IOGP \& IPIECA (2020), a indústria de petróleo e gás adoptou os seguintes estágios principais que podem ser aplicados à maioria projectos:

$\neg$ Exploração/Avaliação;

$\neg$ Desenvolvimento do projecto;

$\neg$ Operações;

$\neg$ Cessação de produção.

Figura r: Fases e actividades do ciclo de vida de exploração e produção

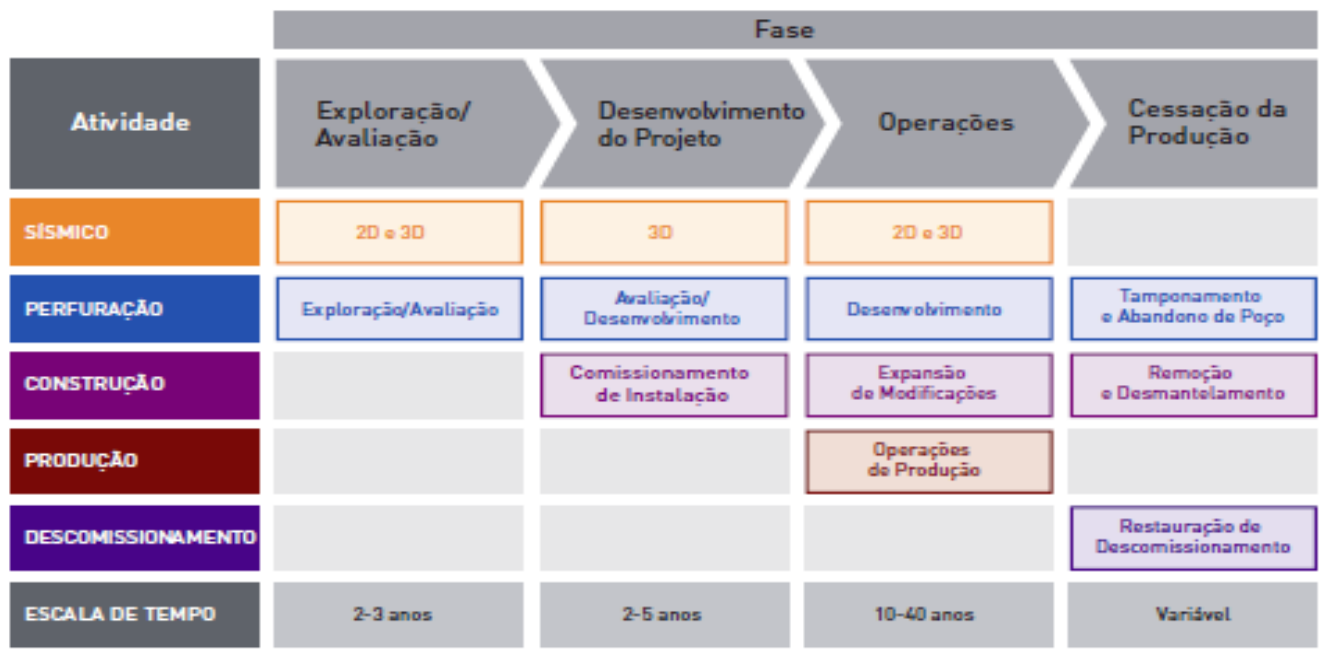

Fonte: IOGP \& IPIECA (2020) 
Todas as fases da indústria de petróleo e gás (estudos de sísmica, a perfuração, a instalação de plataformas, a produção e a cessação de produção), geram expressivos risos ambientais e sociais (LIMMER, 2018).

O tipo e a intensidade dos riscos e impactos que podem surgir devido as actividades de petróleo e gás, dependem de muitos factores, incluindo: A fase e a cronologia de uma actividade ou processo, por exemplo riscos na fase de exploração/avaliação podem ser diferentes e tendem a ser de curta duração, se comparados aos riscos da fase de operações; $O$ tamanho e a complexidade de um projeto ou operação - neste caso impactos de projectos offshore (no mar) diferem de riscos de projectos onshore (em terra); e a natureza e a sensibilidade do ambiente físico e social circundante - a implantação de projectos em áreas sensíveis, ou em áreas próximas as comunidades e as suas actividades, pode aumentar ou não a intensidade dos riscos.

\section{Gestão de Riscos Ambientais}

Os riscos ambientais resultam da associação entre os riscos naturais e os riscos decorrentes de processos naturais agravados pela actividade humana e pela ocupação do território.

Segundo VIEIRA \& BARRETO (2019), a gestão de riscos é o conjunto de procedimentos por meio dos quais as organizações identificam, analisam, avaliam, tratam e monitoram os riscos que podem afectar negativamente o alcance dos objectivos.

Está ligada a uma metodologia de análise da avaliação do risco, voltada para estimar a probabilidade de ocorrência e o impacto, estudando medidas para evitar, reduzir, assumir ou transferir os riscos (AQUINO et al., 2017).

A avaliação de riscos possui laços com a Avaliação de Impactos Ambientais (AIA). Esta avaliação busca identificar, prever possíveis consequências indesejadas provenientes de uma ação sobre a qualidade ambiental e saúde humana (BÊRREDO, 2010).

A avaliação de riscos constitui uma etapa chave no processo de prevenção, na medida em que, ao permitir conhecer o risco, contribui com informação muito 
importante para o planeamento das intervenções preventivas adequadas (MENDONÇA, 2013).

A gestão de riscos é um instrumento que contribui para melhorar o desempenho por meio da identificação de oportunidades e a redução da probabilidade e/ou impacto dos riscos, além de apoiar os esforços de garantia da conformidade dos agentes aos princípios éticos e às normas legais. Para a gestão de ricos é necessário, primeiro conhecer os tais riscos, e este conhecimento só pode ser adquiro a partir da avaliação dos mesmos. A referência principal para a avaliação dos riscos ambientais é o próprio Homem, com as possibilidades de ser atingido pelas transformações do ambiente, mesmo que anteriormente afectando outros seres vivos.

\section{I.I Comunicação de riscos por consulta pública e suas modalidades}

A comunicação de risco surgiu para informar sobre os riscos para a segurança e a saúde que as pessoas estão expostas, sendo que um programa de comunicação pública deve ser realizado com o intuito de levar à sociedade informações verdadeiras a respeito dos riscos reais e benefícios de dada situação. Além de permitir a população colocar suas opiniões, dúvidas e receios, a unilateralidade da informação (especialista para leigo) deve ser superada para uma comunicação completa, este deve ser um processo interativo de troca de informações (AQUINO et al., 2017).

De acordo com MONTEIRO (2009:160), a comunicação de riscos pode ser definida como "um processo interativo de troca de informações e de opiniões entre indivíduos, grupos e instituições, envolvendo mensagens sobre a natureza do risco e outras, que expressam preocupações, opiniões ou reações às mensagens de risco ou os arranjos legais e institucionais para o gerenciamento dos riscos.

Refere-se "a qualquer comunicação pública ou privada para trocar informações e opiniões com os indivíduos sobre a existência, a natureza, a forma, a gravidade ou a aceitabilidade dos riscos" .... "Focaliza uma transferência intencional de informações de especialistas para não especialistas, com vista a responder às preocupações ou necessidades do público leigo quanto a um determinado perigo - real ou percebido”. (MONTEIRO, 2009:160) 
O crescente interesse público pelas questões ambientais, em particular os riscos de impactos ambientais negativos provocados pelos projectos de desenvolvimento, vem impondo às empresas uma revisão de sua estratégia da gestão ambiental, com a comunicação de risco tornando-se um dos elementos decisivos na gestão dos mesmos.

As situações de risco ambiental, envolvendo potenciais de ocorrências com efeitos severos sobre o ambiente e a população, geram dinâmicas específicas de conflitos. Incidem como factores de conflito as diferenças de percepção sobre os riscos ligados à poluição. Diferentemente dos técnicos, o público reage com indignação, pois acredita-se que poluir é errado. Outro fator de indignação é saber quem gera o risco, se estamos expostos a riscos gerados por terceiros, e se o gerador do risco é um ator de grande poder, ou se há manipulação das informações (BÊRREDO, 20I0).

Figura 2: Componentes-chave da Participação dos Interessados

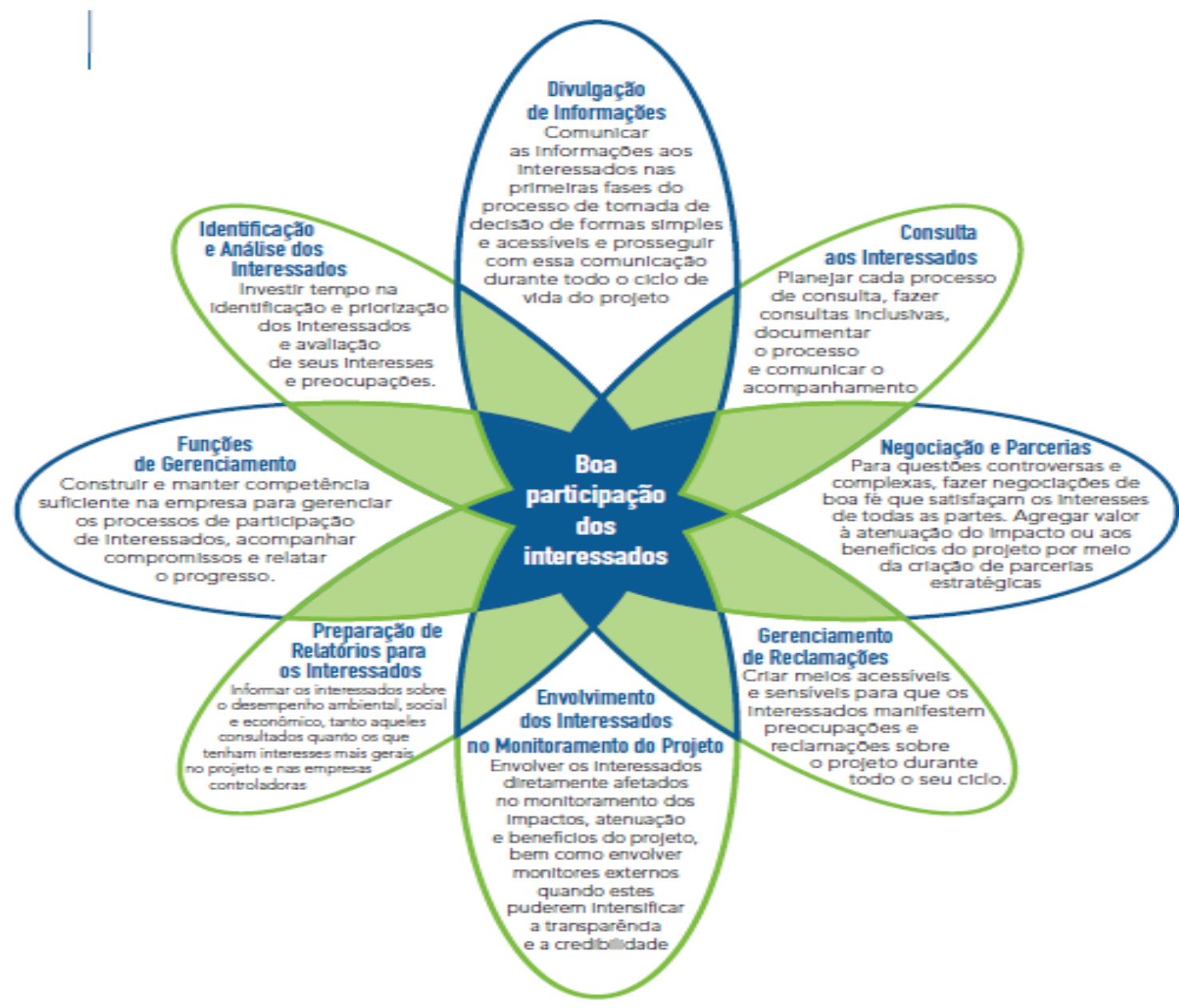

Fonte: Participação dos interessados: Manual de Melhores Práticas para Fazer Negócios em Mercados Emergentes - IFC, 2007 
A informação e comunicação são componentes que permitem aos integrantes da organização conhecer, coletcar e transmitir as informações necessárias para desempenhar suas responsabilidades na gestão de riscos e outras operações da organização (VIEIRA \& BARRETO, 2019).

Ainda de acordo com VIEIRA \& BARRETO (2019), a comunicação e consulta são fundamentais, pois permitem aprimorar a definição do contexto, assegurar a transparência, identificar adequadamente os riscos, assegurar a incorporação das diversas percepções, garantir o apoio necessário à implementação do plano de tratamento de riscos.

\subsection{Consultas públicas na gestão de riscos ambientais decorrentes de grandes projectos}

As consultas públicas facilitam o conhecimento de todos os interessados, estimulando a construção de confiança entre as partes. Essa construção de confiança é fundamental para assegurar que as decisões que serão tomadas no final da consulta tenham dado oportunidade a todas as partes de compreender as diferentes metas a sere alcançadas com o projecto, incluindo os impactos derivados.

De acordo com KVAM (2017), os níveis de consulta e interação podem incluir:

\section{- O compartilhamento de informações como uma comunicação basicamente} unidirecional.

Essa abordagem pode ser apropriada como principal forma de envolvimento com o público em circunstâncias de baixo risco, nas quais o projecto não procura activamente engajar as comunidades ou outras partes interessadas em um diálogo.

O envolvimento consiste principalmente na divulgação para o público de informações relacionadas ao projeto, de forma transparente e acessível, e na oferta de um modo por meio do qual o público possa solicitar informações adicionais ou transmitir suas preocupações e recomendações.

\section{- A consulta como um diálogo de duas vias}

Nos projectos de risco e complexidade moderados e nos casos em que existe o potencial de impactos adversos que deflagrariam políticas de salvaguardas, as partes interessadas são consultadas por meio de um processo activo de via dupla para 
envolvimento e diálogo. As informações precisam ser compartilhadas com as partes interessadas pertinentes, geralmente de forma desagregada, de modo a refletir o contexto local, e os pontos de vista das partes interessadas devem ser registados, documentados e considerados.

\section{- Participação e fortalecimento}

Projectos de risco e complexidade elevados exigem um processo mais significativo e embasado de envolvimento com as partes interessadas. Isso reforça os princípios de diálogo mencionados, mas implica a participação mais ativa das partes interessadas na definição e implementação dos aspectos relevantes de um projecto. Em determinadas circunstâncias de alto risco, as políticas e as boas práticas exigem que as partes interessadas tenham voz ativa no processo decisório do projeto e que um grau de autoridade decisória seja transferido para as comunidades locais e grupos de partes interessadas. Um exemplo disso é a situação na qual um projecto requer a concordância ou consentimento formal das partes interessadas afetadas (KVAM, 2017).

A análise dos riscos de um projecto deve considerar tanto os riscos de impactos adversos causados por ele às pessoas ou ao meio ambiente como os riscos de que ele não consiga atingir seus objectivos.

Para KVAM (2017), ao identificar questões prioritárias para consulta e interação com as partes interessadas, é útil agrupar os riscos em três categorias, em termos de possíveis impactos adversos de/para o projecto:

- Impactos directos: impactos adversos causados pelo projeto e atribuíveis diretamente a ele, como o deslocamento provocado pela aquisição de terras ou os impactos negativos sobre os habitats naturais.

- Impactos indirectos e cumulativos: impactos em que o projecto é um entre vários factores contribuintes. Exemplos: o influxo de mão-de-obra causado pelo aumento das oportunidades econômicas para o qual o projeto contribuiu, o trabalho infantil ou forçado em uma cadeia de suprimentos, a redução da renda dos comerciantes locais em caso de desvio de uma rodovia e o aumento da poluição em uma bacia hidrográfica onde haja muitas outras fontes de poluição.

- Risco contextual: há factores de risco que são atribuídos ao projecto, mas para os quais ele nem contribui, embora possam agravar eventuais riscos específicos para as 
pessoas, o meio ambiente ou o sucesso do próprio projecto. Os riscos dessa categoria incluem conflitos e violência, instabilidade política, fragilidade das estruturas de governança, tensão étnica e religiosa, vulnerabilidade e baixa resiliência ao choque entre as populações afectadas e riscos decorrentes de desastres naturais ou da mudança do clima (KVAM, 2017).

O plano de análise e consulta às partes interessadas deve considerar como o projeto pode afetar homens e mulheres de forma diferente e assegurar que as preocupações das mulheres sejam levadas em consideração durante o processo de consulta (PARAGUAI, 2007), apud (KVAM, 2017).

\section{MATERIAIS E MÉTODOS}

Para a realização do presente trabalho, o procedimento metodológico utilizado foi a pesquisa bibliográfica, a partir das leituras realizadas e selecção de conteúdos, em materiais como livros, revistas, artigos e legislações.

\section{RESULTADOS}

\subsection{Indústria de Petróleo e Gás em Moçambique}

A pesquisa de hidrocarbonetos em Moçambique data de 1904, quando iniciaram as primeiras actividades de pesquisa em Inhaminga e Pande, onde foram descobertas bacias sedimentares de grande espessura com perspectivas de ocorrência de petróleo e gás. Porém, as tecnologias usadas na altura contribuíram para o fracasso, mas com o envolvimento de algumas companhias de petróleo, intensificaram-se as pesquisas, com maior incidência na zona do litoral, onde foram descobertos os campos de gás de Pande em 196i, de Búzi em i962 e Temane em i967 (MOSSE e SELEMANE, 2008).

Alguns factores associados a instabilidade política e a falta de mercado, ditaram o fracasso da exploração do gás nos anos setenta, tendo sido retomadas nos anos oitenta, período este marcado pela aprovação da lei de petróleos (Lei no3/8I), criação da Empresa Nacional de Hidrocarbonetos (ENH), intensificação dos trabalhos de prospecção e sondagem dos furos em Pande, pesquisas em Mocímboa da Praia e XaiXai. 
Em Outubro do ano 200o, foram assinados acordos entre o Governo, a ENH e a Sasol, marcando assim o desenvolvimento da indústria do gás em Moçambique (MOSSE e SELEMANE, 2008).

Este período foi igualmente marcado pela aprovação da nova lei de petróleo (Lei no 3/200I) e em seguida o seu regulamento, retirando assim o monopólio da ENH nos processos de pesquisa, passando a participar como associada e representando os interesses comerciais do estado nos vários projectos.

A luz do Decreto no 25/2004 de 20 de Agosto, foi criado o Instituto Nacional de Petróleo (INP), entidade responsável pela administração e promoção de operações petrolíferas.

A partir do ano 2010, começaram as primeiras descobertas de gás na Bacia do Rovuma, pelas companhias Americana Anadarko (actualmente Total Exploration Production Mozambique) e posteriormente pela Italiana ENI, marcando assim uma nova fase no que diz respeito à pesquisa de hidrocarbonetos, pois pelas quantidades estimadas colocaram Moçambique na lista dos maiores produtores de Gás no Mundo.

Tabela I: Actividades de petróleo e Gás em Moçambique

\begin{tabular}{|c|c|c|c|c|}
\hline $\begin{array}{l}\text { Áreas de Concessão } \\
\text { = Operadores }\end{array}$ & $\begin{array}{l}\text { Fase das } \\
\text { Operações }\end{array}$ & $\begin{array}{l}\text { Projecto em fase de } \\
\text { Desenvolvimento }\end{array}$ & $\begin{array}{l}\text { Localização do } \\
\text { Reservatório }\end{array}$ & $\begin{array}{l}\text { Localização } \\
\text { do das } \\
\text { infraetruturas } \\
\text { de produção }\end{array}$ \\
\hline $\begin{array}{l}\text { Jazigos de Pande e } \\
\text { Temane } \\
\text { (PPA/APP) = Sasol } \\
\text { Petroleum Temane } \\
(\mathrm{SPT})\end{array}$ & Desenvolvimento & $\begin{array}{l}\text { Projecto de Produção } \\
\text { de Gás de } \\
\text { Pande/Temane - } \\
\text { Blocos de Pande e } \\
\text { Temane, Bacia de } \\
\text { Moçambique }\end{array}$ & $\begin{array}{l}\text { Onshore } \quad(\mathrm{em} \\
\text { terra) }\end{array}$ & $\begin{array}{l}\text { Onshore (em } \\
\text { terra) }\end{array}$ \\
\hline $\begin{array}{l}\text { Blocos de Pande e } \\
\text { Temane } \\
(\mathrm{PSA} / \mathrm{CPP}) \text { = Sasol } \\
\text { Petroleum } \\
\text { Mozambique (SPM) }\end{array}$ & Desenvolvimento & $\begin{array}{l}\text { Projecto de Produção } \\
\text { de Petróleo Leve }\end{array}$ & $\begin{array}{l}\text { Onshore (em } \\
\text { terra) }\end{array}$ & $\begin{array}{l}\text { Onshore (em } \\
\text { terra) }\end{array}$ \\
\hline $\begin{array}{l}\text { Bloco de Buzi = Buzi } \\
\text { Hydrocarbons }\end{array}$ & Pesquisa & Não aplicável & Não aplicável & Não aplicável \\
\hline $\begin{array}{l}\text { Àrea } 4 \text { da Bacia do } \\
\text { Rovuma }\end{array}$ & Desenvolvimento & $\begin{array}{l}\text { Projecto FLNG Coral } \\
\text { Sul }\end{array}$ & $\begin{array}{l}\text { Offshore (no } \\
\text { mar) }\end{array}$ & $\begin{array}{l}\text { Offshore (no } \\
\text { mar) }\end{array}$ \\
\hline $\begin{array}{l}\text { Mozambique } \\
\text { Rovuma Venture } \\
(\mathrm{MRV})\end{array}$ & & $\begin{array}{l}\text { Projecto } \\
\text { LNG }\end{array}$ & $\begin{array}{l}\text { Offshore } \\
\text { mar) }\end{array}$ & $\begin{array}{l}\text { Onshore (em } \\
\text { terra) }\end{array}$ \\
\hline $\begin{array}{l}\text { Área I da Bacia do } \\
\text { Rovuma = Total } \\
\text { Exploration }\end{array}$ & Desenvolvimento & $\begin{array}{l}\text { Projecto LNG } \\
\text { Golfinho/Atum } \\
\text { (Mozambique LNG) }\end{array}$ & $\begin{array}{l}\text { Offshore } \\
\text { mar) }\end{array}$ & $\begin{array}{l}\text { Onshore (em } \\
\text { terra) }\end{array}$ \\
\hline
\end{tabular}




\begin{tabular}{|c|c|c|c|c|}
\hline $\begin{array}{l}\text { Production } \\
\text { Mozambique }\end{array}$ & & & & \\
\hline $\begin{array}{l}\text { Área A5-B = } \\
\text { ExxonMobil } \\
\text { Exploration and } \\
\text { Production } \\
\text { Mozambique } \\
(\text { Angoche A5-B) } \\
\text { B.V }\end{array}$ & Pesquisa & Não aplicável & $\begin{array}{l}\text { Offshore (no } \\
\text { mar) }\end{array}$ & Não aplicável \\
\hline $\begin{array}{l}\text { Área } \mathrm{Z}_{5}-\mathrm{D} \\
\text { ExxonMobil } \\
\text { Exploration } \\
\text { Production } \\
\text { Mozambique } \\
\left(\text { Zambezi } Z_{5}-\mathrm{D}\right) \text { B.V }\end{array}$ & Pesquisa & Não aplicável & $\begin{array}{l}\text { Offshore (no } \\
\text { mar) }\end{array}$ & Não aplicável \\
\hline $\begin{array}{l}\text { Área } Z_{5}-\mathrm{C} \\
\text { ExxonMobil } \\
\text { Exploration } \\
\text { Production } \\
\text { Mozambique } \\
\left(\text { Zambezi } Z_{5}-\mathrm{C}\right) \\
\text { B.V }\end{array}$ & Pesquisa & Não aplicável & $\begin{array}{l}\text { Offshore (no } \\
\text { mar) }\end{array}$ & Não aplicável \\
\hline $\begin{array}{l}\text { Área } \mathrm{PT}_{5}-\mathrm{C}=\text { Sasol } \\
\text { PetroMoz }\end{array}$ & Pesquisa & Não aplicável & $\begin{array}{l}\text { Offshore (no } \\
\text { mar) }\end{array}$ & Não aplicável \\
\hline $\begin{array}{l}\text { Área As-A = Eni } \\
\text { Mozambico S.p.A }\end{array}$ & Pesquisa & Não aplicável & $\begin{array}{l}\text { Offshore (no } \\
\text { mar) }\end{array}$ & Não aplicável \\
\hline $\begin{array}{l}\text { Temane (Moç.) a } \\
\text { Secunda (RSA) }\end{array}$ & $\begin{array}{l}\text { Transporte de } \\
\text { Gás }\end{array}$ & Não aplicável & Não aplicável & Não aplicável \\
\hline $\begin{array}{l}\text { Ressano Garcia a } \\
\text { Matola }\end{array}$ & $\begin{array}{l}\text { Transporte de } \\
\text { Gás }\end{array}$ & Não aplicável & Não aplicável & Não aplicável \\
\hline
\end{tabular}

Fonte: Adaptado do Website do Instituto Nacional de Petróleos \& Contratos de Concessão em Vigor actualizado em Julho de 202I (http://www.inp.gov.mz/pt).

Segundo dados do INP (Instituto Nacional de Petróleo), e olhando para os projectos de Petróleo e Gás em fase de desenvolvimento, nomeadamente: Projecto de Produção de Gás de Pande/Temane - Jazigos de Pande e Temane - Bacia de Moçambique, Projecto de Produção de Petróleo Leve - Blocos de Pande e Temane, Projecto LNG Golfinho/Atum (Mozambique LNG), Projecto Rovuma LNG e o Projecto FLNG Coral Sul: somente este ultimo é que os seus reservatórios de hidrocarbonetos e as estruturas de produção, ambos estão localizadas offshore (no mar), os restantes projectos em fase de desenvolvimento existentes em Moçambique, as estruturas de produção estão ou estarão localizadas onshore (em terra).

De acordos com dados do INP, todos os projectos existentes onshore (em terra) em fase de desenvolvimento envolveram ou envolverão o processo de reassentamento de populações com vista a dar lugar a implantação dos empreendimentos necessários para a execução das actividades de petróleo e gás. 
A necessidade ou não de reassentamento das populações e de suas actividades económicas, torna os projectos diferentes no que se refere a gestão de riscos e consequentemente na comunicação dos riscos existentes. Uma vez que para além de gerir os riscos ambientais, este tipo de projectos devem também gerir as elevadas expectativas sociais das partes interessadas e afectadas (stakeholders).

O Decreto - Lei 130/2012 de 8 de Agosto, estipula que o reassentamento visa impulsionar o desenvolvimento sócio-económico do país e garantir que a população afectada, tenha uma melhor qualidade de vida, equidade social, tendo em conta a sustentabilidade dos aspectos físicos, ambientais, sociais e económicos. E um plano de reassentamento deve ser elaborado para o efeito.

Caso não seja administrado adequadamente, o reassentamento pode resultar em adversidades e empobrecimento de longo prazo para as comunidades afectadas, bem como em danos ao meio ambiente e impactos sócio-económicos adversos nas áreas para onde tenham sido reassentadas. Por essas razões, medidas apropriadas devem ser cuidadosamente planejadas e executadas, para minimizar os impactos adversos causados às pessoas deslocadas e às comunidades anfitriãs (IFC, 2012).

\subsection{Avaliação de riscos ambientais em Moçambique}

A gestão de riscos ambientais em Moçambique, é o culminar do processo de avaliação, em que os riscos e impactos são identificados, avaliados e são aplicadas as medidas de gestão.

O licenciamento ambiental é o processo pelo qual o órgão legalmente responsável pelo meio ambiente avalia e concede licença de instalação e operação para empreendimentos que utilizam recursos naturais e possam causar danos ou impactos que afectem o meio ambiente e a qualidade de vida das populações. Este processo demostra-se ser um importante instrumento de gestão ambiental e controle social e, prevê acções que se fazem necessárias para minimizar impactos, considerando-se as disposições legais e regulamentares (SILVA et al., 2008).

Em Moçambique o licenciamento ambiental, é regulado pelo decreto 54/2015 de 3I de Dezembro de 2015, no qual projectos considerados de categoria A (são acções que afectam significativamente seres vivos e áreas ambientalmente sensíveis e os seus impactos são de maior duração, intensidade, magnitude e significância) e $\mathrm{A}+$ (são 
acções que devido a sua complexidade, localização e magnitude dos possíveis impactos, merecem não só um elevado nível de vigilância social e ambiental, mas também o envolvimento de especialistas nos processos de avaliação de impacto ambiental) são requeridos de realizar consultas públicas durante o processo de avaliação de impacto ambiental.

\subsection{Avaliação de riscos ambientais no sector de petróleo e gás}

Embora as suas actividades produtivas gerem altos rendimentos e promovam o desenvolvimento, grandes impactos ambientais estão aliados a estas actividades, como: abertura de estradas, picadas e clareiras; danos à vegetação, solo e fauna a partir da construção de instalações auxiliares; interferência nos recursos hídricos subterrâneos causados pelos estudos hidrogeológicos; levantamentos geofísicos com possibilidade de gerar ruídos, explosões e vazamento de combustíveis; perfuração de poços para pesquisa e preparação da lavra, com a possibilidade de prejuízo à flora, às águas subterrâneas, ao solo e à segurança de comunidades (OLIVEIRA \& SANTOS, 2007).

A avaliação de risco ambiental durante o processo de licenciamento ambiental

é muito importante, pois nem todos os impactos conseguem ser avaliados suficientemente através da avaliação de impacto ambiental, e assim, a análise de risco é uma ferramenta apropriada para contribuir na escolha da melhor alternativa de projecto com o mínimo risco ao meio ambiente.

Em Moçambique, tanto a Constituição República, como a Lei do Ambiente determinam os direitos dos cidadãos a ter informação sobre e participar na tomada de decisões sobre as actividades que poderão afectar o ambiente. Nesse sentido, o processo de participação pública identifica e consulta as partes interessadas e afectadas - PI \& A's, sobre os riscos que estes estarão expostos.

As actividades de petróleo e gás são regidas por um decreto específico, que é o $56 / 2010$ de 22 de Novembro de 2010, no qual as actividades de categoria A (actividades relacionadas com o desenvolvimento, produção, construção e operação de sistemas de oleoduto ou gasoduto e desmobilização e outras actividades a serem desenvolvidas em ecossistemas sensíveis e áreas de conservação) e actividades de categoria B 
(actividades relacionadas com a pesquisa exceptuando em áreas de conservação e ecossistemas sensíveis) são requeridas de realizar consultas públicas).

VIEIRA \& BARRETO (2019), reconhecem que a gestão de riscos é um processo contínuo que flui pela organização, em todos os níveis, aplicado à definição das estratégias conforme o apetite de risco estabelecido. Tendo nesse sentido a comunicação e partilha de informação seu contributo no processo.

Para o caso particular de projectos de petróleo e gás, a Lei 20/2014 de I8 de Agosto (Lei de Petróleos), faz referência sobre a obrigatoriedade de fornecer a informação prévia às comunidades sobre o início das actividades de pesquisa, devendo o governo criar condições para o envolvimento e participação das comunidades nas áreas onde se encontram implantados estes empreendimentos.

\subsection{A importância da Comunicação de riscos nos projectos de petróleo e gás em Moçambique}

Portanto, de acordo com JUNIOR, (s/d) para que a comunicação de risco seja bem-sucedida, e seus ganhos retidos, é preciso adoptar modelos que favoreçam o diálogo, tornando os interesses, valores e preocupações do público conhecidos e considerados pelos técnicos na formação do processo decisório.

A Comunicação de Risco, portanto, é parte integrante do processo de gerenciamento de riscos, responsável de integrar e informar aos stakeholders (partes interessadas e afectadas), maneiras e procedimentos de como devem agir perante ameaças, evitando que se manifestem e se tornem crises (RINALDI, 2007).

A comunicação do risco contribui para gerar e receber as informações necessárias para que as partes interessadas não somente compreendam as iniciativas e os processos de decisão tomados pelas organizações para gerenciar seus riscos, mas também, para promover e desenvolver a percepção a respeito dos perigos e riscos decorrentes da natureza da actividade desenvolvida.

\subsection{Comunicação de Riscos nos Projectos que envolvem reassentamento}

De acordo com o INAS (2019), uma vez que neste tipo de projectos a componente social pode ser de maior relevância para os diferentes stakeholders, entende-se que uma abordagem faseada e diferenciada dos riscos pode contribuir 
melhor para uma adequada partilha de informação e colecta das opiniões das partes interessadas e afectadas, seguindo as seguintes fases:

Primeira fase - consulta pública apenas dos riscos e impactos sociais e económicos, esta pode ser realizada para as partes interessadas e afectadas voltadas aos riscos e impactos sociais.

Segunda fase - consulta pública para discussão dos riscos ambientais - esta realizada para as partes interessadas e afectadas voltadas aos riscos ambientais.

Quanto mais informados sobre as etapas da obra e programas ambientais, maior é o entendimento pela população atingida, o que gera confiança e cooperação com o subprojecto (INAS, 2019).

\subsection{Comunicação de Riscos nos Projectos que não envolvem reassentamento}

A semelhança do que acontece com outros projectos com impactos sócioeconómicos e ambientais, a comunicação dos riscos para estes projectos deve começar nas primeiras fases do processo de identificação de riscos e dos impactos sócioambientais e continuar ininterruptamente à medida que os riscos e impactos aparecerem, devendo igualmente basear-se na divulgação e disseminação prévias de informações relevantes de forma fácil e compreensível para as comunidades afectadas (INAS, 2019).

Para os projectos de petróleo e gás que não envolvem reassentamento, caracterizando-se por serem implantados offshore (no mar), a partilha de informação poderá ser conjunta, uma vez que os riscos sociais e ambientais são limitados e a espectativa social não é elevada, se comparado aos projectos que ocorrem onshore (em terra).

\subsection{Consultas públicas no contexto moçambicano}

As Consultas públicas são um procedimento exigido na legislação nacional sobre Avaliação do Impacto Ambiental, no Decreto 45/2004 e Diploma Ministerial para o Processo de Participação Pública nos Estudos de Impacto Ambiental, Diploma Ministerial 130/2006. É igualmente requisito do Grupo do Banco Mundial, incluindo o IFC (International Financial Corporation). 
A luz do decreto-lei 54/2015 de 3r de Dezembro, Consulta pública é definida como sendo o processo de auscultação do parecer dos diversos sectores da sociedade civil, incluindo pessoas colectivas ou singulares, directa ou indirectamente interessadas e/ou principalmente afectadas pela actividade proposta.

A consulta pública não deve ser considerada como uma actividade isolada. É parte integrante da Avaliação de Impacto Ambiental e deve contribuir para subsidiar o exercício de identificação de consequências de uma actividade sobre o ambiente, incluindo repercussões na vida económica e social da área de inserção geográfica das acções de desenvolvimento (Diploma Ministerial 130/2006).

O Regulamento de avaliação de Impacto Ambiental (Decreto 54/2015) obriga o proponente do projeto a efectuar consulta e participação pública, particularmente no caso em que seja restringido o uso dos recursos naturais pelo projeto ou em caso de deslocação física de pessoas como consequência da implementação do projecto.

Envolver as partes interessadas e afectadas em questões que afectam directa ou indirectamente o desenvolvimento das organizações, é torná-los parte essencial no processo de comunicação e com isso, despertar em cada um o sentimento de pertencer e crer, o que solidifica sua confiança e a credibilidade.

Tornando-se assim num mecanismo de comunicação de "mão dupla", o que para LOURENÇO \& MARCHIORI (20I2) facilita o fluxo das mensagens e das informações entre emissor e receptor, favorecendo a participação dos públicos de interesse, e que para que este processo ocorra, a organização precisa adotar uma postura "aberta" e transparente, o que favorece a construção da confiança e credibilidade de seus públicos, que estão cada vez mais atentos e exigentes em relação às atitudes da organização.

Olhado para os projectos de Desenvolvimento, estas, visam colher as sensibilidades das partes interessadas e afectadas (PI \& A's) sobre os potenciais impactos do projecto em suas vidas e meios de subsistência. Este envolvimento é um direito consagrado na legislação de Avaliação de Impacto Ambiental (Decreto 54/2015), e na Directiva Geral para a Participação Pública no Processo de Avaliação do Impacto Ambiental (Diploma Ministerial 130/2006).

De acordo com FARIA \& SILVA (2017), os méritos da participação pública nas tomadas de decisões incluem: atender à necessidade de diversas culturas, utilizar o 
conhecimento leigo e local, examinar o conhecimento especializado, legitimar os resultados dos processos de tomada de decisão, democratizar a tomada de decisão, aprendizado social, orientar o público, incorporar valores locais, construir confiança e reduzir custos de atrasos e de conflitos.

\section{CONCLUSÃO}

A comunicação de risco, por meio de consultas públicas, mostra-se como um elemento preponderante para informar às pessoas sobre os riscos que estão expostas, assim como na gestão de riscos para as organizações. É através da comunicação de riscos por meio de consultas públicas que se vê reforçada a participação pública nos processos de tomada de decisão, uma vez que se faz necessário expor a lógica dos argumentos, favorecendo a transparência dos processos e a recepcção aberta de opiniões públicas. Dessa forma, o direito de participação não equivale apenas ao acesso à informação, mas envolve também o poder de influenciar nas decisões. Este modelo de Comunicação permeia todas as etapas da gestão de riscos e se configura como fundamental neste processo, uma vez que se torna responsável por comunicar aos stakeholders os procedimentos adotados na gestão, e também fazer com que estes públicos entendam e se conscientizem a respeito dos riscos e das práticas adotadas pela organização, com a finalidade de minimizá-los, porem, para que as consultas públicas sejam eficazes, estas devem ser estruturadas para determinados grupos alvos e temáticas específicas, segundo a complexidade do projecto. Pode-se afirmar que ficou evidente que a comunicação de riscos auxilia na construção da confiança e credibilidade das empresas aos olhos do público, colaborando para um relacionamento duradouro.

Mas recomenda-se a elaboração de instrumentos legais que orientem os processos de consultas públicas específicos para projectos de petróleo e gás offshore (no mar) e onshore (na terra), uma vez que as exigências na contínua e mais frequente partilha de informação são diferentes, visto que os projectos que ocorrem em terra, podem envolver deslocamento de pessoas para sua implantação. Neste sentido, a comunicação de riscos por meio de consultas públicas em projectos que envolvem reassentamento de populações entende-se que devem ser mais frequentes, e mais elaboradas, e os projectos que ocorrem offshore (no mar), são caracterizados por riscos 
sociais limitados, assim como os ambientais, excepto nos casos de emergências devido a derrames de hidrocarbonetos no mar.

Para os projectos de petróleo e gás em Moçambique, a comunicação de riscos poderia se tornar mais eficaz, se as consultas públicas fossem obrigatórias não só durante o processo de avaliação de riscos e impactos, mas também durante as diferentes fases dos projectos.

\section{REFERÊNCIAS BIBLIOGRÁFICA}

ARQUINO, Paletta e ALMEIDA, J. R. Risco Ambiental. São Paulo. Editora Blucher. 2017.

BERREDO, V. D. Avaliação de Riscos Ambientais em áreas contaminadas: Uma proposta metodológicas. Rio de Janeiro. Universidade Federal de Rio de Janeiro. 2010.

DI GIULO, Marques. Governança do risco: Uma proposta para lidar com riscos ambientais no nível local. Desenvolvimento e Meio Ambiente. On line. Disponível na internet via correio electrónico://http:doi. Doi. Org. 10.538odma. v28io.30171. 2013.

IOGP e IPIECA. Gestão ambiental no sector de exploração e produção de petróleo e gás. 2020.

JUNIOR, L. C. de M. (s d). Comunicação de Riscos Tecnológicos Ambientais.

KVAN, Reidar. Consulta significativa as partes interessadas: Série do BID sobre riscos e oportunidades ambientais e sociais. Brasília. Banco Interoamericano de Desenvolivimento. 2017.

FARIA, G. C.; SILVA, F. M. Participação pública no processo de avaliação de impacto ambiental no Estado do Espírito Santo. Desenvolv. Meio Ambiente, v. 43, Edição Especial: Avaliação de Impacto Ambiental, p. 139-151. 2017

INTERNATIONAL FINANCIAL CORPORATION (IFC) Participação dos interessados: Manual de Melhores Práticas para Fazer Negócios em Mercados Emergentes. 2007 .

INTERNATIONAL FINANCIAL CORPORATION (IFC). Padrões de Desempenho sobre Sustentabilidade Socioambiental. Banco Mundial. 2012

INSTITUTO NACIONAL DE PETRÓLEOS (INP). Contractos de Concessão em Vigor .[online] Disponível na Internet http://www.inp.gov.mz/. Actualizado em Julho de 2021

JUNIOR, L. C. de M. (s/d). Comunicação de Riscos Tecnológicos Ambientais. 
KVAM, Reidar. Consulta significativa as partes interessadas: Série do BID sobre riscos e oportunidades ambientais e sociais. Brasília. Banco Interamericano de Desenvolvimento. 2017.

LIMMER F. Da C. "O Licenciamento Ambiental da Indústria Petrolifera". Brasil, Revista Brasileira de Direito do Petróleo, Gás e Energia, v. 5, n.I, p. 225-242. 2018.

LOURENCO, M. R, e MARCHIORI, M. A prática da comunicação de risco nas organoizações. Universidade Estadual de Londrina. Facesi em Revista. ISSN 2177 6636. 2016.

MARIANO, J.B. Proposta de Metodologia de Avaliação Integrada de Riscos e Impactos Ambientais para Estudos de Avaliação Ambiental Estratégica do Sector de Petróleo e Gás Natural em Áreas Offshore. Tese de Doutoramento em Ciências em Planejamento Energético. Rio de Janeiro. Universidade Federal do Rio de Janeiro. 2007.

MENDONÇA, A. L. P.V. Métodos de Avaliação de Riscos Contributo para a Sua Aplicabilidade no Sector da Construção Civil. Tese de Mestrado em Engenharia Ambiental. Algarve. Universidade do Algarve. 2013

MENEZES, L.O. PARISI, M.G; RUCHKYS, Ú.A.; \& JARDIM, A.H. Comunicação em Geociências na Gestão de Riscos e Desastres Ambientais. Anuário do Instituto de Geociências. 44: 37273. DOI 1982-3908_2021_44_37273. 2021

MONTEIRO, Mário. Ciência e Risco: as controvérsias como procedimento da comunicação pública em um contexto democrático. Tese de Doutoramento. Brasília Universidade de Brasília. 2009.

MOSSE, M., \& SELEMANE, T. Alguns Desafios na Indústria Extractiva em Moçambique (Maputo). CIP - Centro de Integridade Pública. Maputo. 2008

OLIVEIRA, R. C., \& SANTOS, J. B. dos. Gestão Ambiental Nas Empresas do Setor de Petróleo e Gás Em Mossoró-RN. NECTA/CEFET-RN. 2007

REPÚBLICA DE MOÇAMBIQUE, Boletim da República: Decreto-Lei que regula o processo de avaliação de impacto ambiental em Moçambique. In: Boletim da República, 54/2015 de 31 de Dezembro de 2015.

REPÚBLICA DE MOÇAMBIQUE, Boletim da República: Decreto-Lei que regula o processo de reassentamento resultante de actividades económicas de impacto ambiental em Moçambique. In: Boletim da República, 31/2012 de 8 de Agosto de 2012.

REPÚBLICA DE MOÇAMBIQUE, BOLETIM DA REPÚBLICA: Directiva Geral para a Participação Pública, no Processo de Avaliação do Impacto Ambiental em Moçambique. In: Boletim da República, 130/2006 de I9 de Julho de 2006.

REPÚBLICA DE MOÇAMBIQUE, BOLETIM DA REPÚBLICA: Decreto-Lei que regula o processo de avaliação de impacto ambiental em Moçambique. In: Boletim da República, 56/2010 de 22 de Novembro de 2010. 
REPÚBLICA DE MOÇAMBIQUE, BOLETIM DA REPÚBLICA: Decreto-Lei que Cria o Instituto Nacional de Petróleo (INP) e aprova o respectivo Estatuto Orgânico em Moçambique. In: Boletim da República, 25/2004 de 20 de Agosto de 2004.

REPÚBLICA DE MOÇAMBIQUE: INSTITUTO NACIONAL DE ACÇÃO SOCIAL (INAS). Quadro da Política de Reassentamento. Projecto de Protecção Social (PI29524). 2019.

RINALDI, A. A Importância da Comunicação de Risco para as organizações. Dissertação (Mestrado em Gestão Integrada em Saúde do Trabalho e Meio Ambiente) - Centro Universitário SENAC, São Paulo, 2007.

SANTOS, P.V. Impactos Ambientais Causados pela Perfuração de Petróleo. Cadernos de Graduação - Ciências Exatas e Tecnológicas, Sergipe, v. I, n.15, p. 153-163. 2012,

SILVA, J. M. C. da, BOZELLI, R. L., SANTOS, L. F. dos, \& LOPES, A. F. Impactos Ambientais da Exploração e Produção de Petróleo na Bacia de Campos, Rio de Janeiro. IV Encontro Nacional da Anppas. 2008

VIEIRA, J.B, BARRETO, R.T. de. Governança, gestão de riscos e integridade. Brasília. Enap - Fundação Escola Nacional de Administração Pública e SBAP - Sociedade Brasileira de Administração Pública. 2019. 